\title{
Salivary Cortisol Levels throughout Childhood and Adolescence: Relation with Age, Pubertal Stage, and Weight ${ }^{1}$
}

\author{
W. KIESS, ${ }^{2}$ A. MEIDERT, R. A. DRESSENDÖRFER, K. SCHRIEVER, U. KESSLER, A. KÖNIG, \\ H. P. SCHWARZ, AND C. J. STRASBURGER \\ Department Pediatric Endocrinology [W.K., A.M., U.K., H.P.S.], Children's Hospital, University of \\ Munich, D 80337 Munich, Federal Republic of Germany and Department Internal Medicine [R.A.D., K.S., \\ A.K., C.J.S.J, Klinikum Innenstadt, University of Munich, D 80336 Munich, Germany
}

\begin{abstract}
The measurement of cortisol in saliva has become a reliable tool for both the scientist and the clinician for studying adrenal cortical function in the adult. We have measured salivary cortisol in samples from 138 healthy infants, children, and adolescents, and from 14 adults. Saliva samples were obtained at home using a cotton swab and a saliva-collecting tube at 800,1300 , and 1800 $\mathrm{h}$ before meals. Cortisol was measured using a time-resolved fluorescent immunoassay. Cortisol levels in saliva ranged from less than $2 \mathrm{nmol} / \mathrm{L}$ up to more than $100 \mathrm{nmol} / \mathrm{L}$. Cortisol levels were age-dependent. Interestingly, after the age of $6 \mathrm{y}$, cortisol levels correlated significantly with pubertal stages (analysis of
\end{abstract}

ABSTRACT
The measurement of cortisol in saliva provides a reliable tool for investigations of hypothalamus-pituitary-adrenal axis activity (1-11). Saliva samples can be obtained stress-free. In addition, salivary cortisol represents the free fraction of cortisol in plasma and does not depend on salivary secretion rate (flow rate) nor on salivary protein content $(4,5,9,11)$. About $5-10 \%$ of total plasma cortisol is not bound to cortisol-binding globulin (= free plasma cortisol) and diffuses rapidly into saliva. Salivary cortisol measurements have been extensively used in psychobiologic, psychiatric, and adult endocrine research. Surprisingly, relatively little information is available on the use of salivary cortisol determinations in children and adolescents. Importantly, relatively few studies deal with the diurnal variation of cortisol levels in children, developmental and physiologic aspects of adrenal function in young age, and the influence of weight, age, and pubertal development on cortisol levels (12-25). We have measured cortisol levels in saliva samples from 138 healthy infants, children, and adoles-

Received March 31, 1994; accepted October 4, 1994.

Correspondence and reprint requests: W. Kiess, M.D., Children's Hospital, Department General Pediatrics and Nconatology, Justus Liebig University, Feulgenstr. 12, D 35385 Giessen, Germany.

1 Presented in part at the Annual Meeting of the ESPE, Zaragoza, Spain, 1992

2 Present address: Children's Hospital, Department General Pediatrics and Neonatology, Justus Liebig University, Fculgenstr. 12, D 35385 Gicssen, Germany. variance). No sex difference was found. In addition, cortisol morning levels and daily cortisol levels (area under the curve from three measurements) increased with body weight and body mass index. The highest cortisol levels were measured in saliva of children younger than $1 \mathrm{y}$. No circadian variation was evident before the age of $9 \mathrm{mo}$. After 1 y of age, salivary cortisol levels varied in a circadian fashion. The measurement of salivary cortisol levels is an attractive way of testing adrenal function in infants and children. It provides a reliable tool for the determination of the physiology and developmental characteristics of cortisol metabolism. (Pediatr Res 37: 502-506, 1995)

cents and from 14 adults to obtain more insight into regulatory mechanisms of adrenal function throughout childhood and adolescents.

\section{METHODS}

Subjects and study protocol. Saliva samples were obtained in the home setting at 800,1300 , and $1800 \mathrm{~h}$ before meals. Saliva samples were sent to the laboratory by surface mail. A complete medical examination was performed, and height, weight, and pubertal stages were recorded by means of a standardized examination form.

Height, weight, and body mass index values of the subjects were all within the third to 97th percentile range (26). A total of 178 healthy subjects were recruited from an inner city neighborhood (Munich, Germany), the local kindergarden, and local schools to participate in the study. Twenty-six subjects were excluded from the study because one or more of the saliva samples were missing and/or complete anthropometric data were not available at the termination of the study. A complete data set was obtained from 138 healthy infants, children, and adolescents and from 14 adults. The study protocol was approved by the Ethical Commitee of the Bayerische Landesärztekammer (state medical chamber of Bavaria). Written consent was obtained from the parents and/or the subjects. 
Procedures. Saliva was collected by using a cotton swab and a saliva-collecting tube (Salivette, Sarstedt, Germany). In infants below 1 y of age, saliva samples were collected by gentle suction of saliva with a rubber ball pipet. This procedure was not stressful to the infants and was tolerated well. Also, the volume of saliva obtained by this method was sufficient for the cortisol measurements. In infants, children, and adolescents more than 1 y of age, the probands were offered cotton swabs, and the parents and/or the children were asked to keep the swabs in the proband's mouth for 2 min to allow for the accumulation of a sufficient saliva volume (usually more than $200 \mu \mathrm{L}$ ). Because the sensitivity of the assay used is high, only $120 \mu \mathrm{L}$ (50 $\mu \mathrm{L}$ for single determination) of saliva are needed for duplicate determinations of cortisol. Stimulation of saliva flow (i.e. by use of lemon/lime) was not used because of the fear that this might not be tolerated well in the young age group. In the age group between 1 and $3 \mathrm{y}$ of age, seven children refused to participate or were not compliant with the procedure. The saliva samples were centrifuged upon arrival in the laboratory and stored frozen at $-20^{\circ} \mathrm{C}$ until analysis. Centrifugation does not interfere with the recovery rate of added free cortisol in samples of saliva reference standards but gives debris-free salivary plasma that can be pipetted easily.

Salivary cortisol was measured using a time-resolved fluorescent immunoassay as published elsewhere (27). In brief, a cortisol-biotin conjugate was used as the tracer in a solid-phase microtiter plate-based immunoassay using a high affinity anticortisol 3CMO antiserum (27). The signal was detected in a time-resolved fluorescence system (DELFIA, Wallac, Turku, Finland) after a second incubation step with a commercially available streptavidin-europium conjugate (Pharmacia, Freiburg, Germany). The lower detection limit of the assay was $0.43 \mathrm{nM}$ using $50-\mu \mathrm{L}$ saliva samples. The specificity of the assay is defined by an $11.2 \%$ cross-reactivity of the antiserum with cortisone, $0.98 \%$ with corticosterone, $0.0013 \%$ with dexamethasone, and 50.6\% with prednisolone. Results obtained with the time-resolved fluorescent immunoassay method are highly correlated with results obtained using standard RIA (27). The intraassay reproducibility was between 4.0 and $6.7 \%$ in repetitive determinations $(n=37)$ of samples between 2.2 and $13.2 \mathrm{nM}$ cortisol concentration. The respective interassay variation was between 7.1 and $9 \%$ (at 2.2 and $13.2 \mathrm{nM}$ cortisol concentration) $(n=50)$. Mean recovery of cortisol from human saliva is $96.6 \%$ (27).

Statistical analysis was performed using BMDP statistical software programs (BMDP, Statistical Software, Los Angeles, CA) (analysis of variance, regression analysis as indicated).

\section{RESULTS}

Cortisol levels in saliva from healthy children and adolescents. Salivary cortisol levels were measured in morning, midday, and evening saliva samples as described in "Methods." Percentiles of salivary cortisol levels were calculated using BMDP Statistical Software as indicated. Subjects were grouped according to age as follows: $0-1$ y $(n=10)$, above $1-4$ y $(n=17)$, above $4-8$ y $(n=22)$, above $8-10$ y $(n=19)$, above $10-13$ y $(n=33)$, above $13-17$ y $(n=31)$, and above
17 y $(n=20)$. Figure 1 shows the fifth, 50th, and 95th percentile for morning (Fig. 1A), midday (Fig. 1B), and evening (Fig. 1C) cortisol concentrations in saliva. Large interindividual variations of midday and evening cortisol levels were measured in saliva samples from children under the age of $1 \mathrm{y}$. In the age groups $1-4,4-8$, and 8-10 y, much less variation was measured. Interindividual variability increased later in adolescence and in adulthood. In addition, morning salivary cortisol varied considerably at all ages.

Circadian variation of salivary cortisol levels in healthy children and adolescents. Salivary cortisol levels were significantly higher in the morning than at midday or evening in

cortisol (nmol/l)
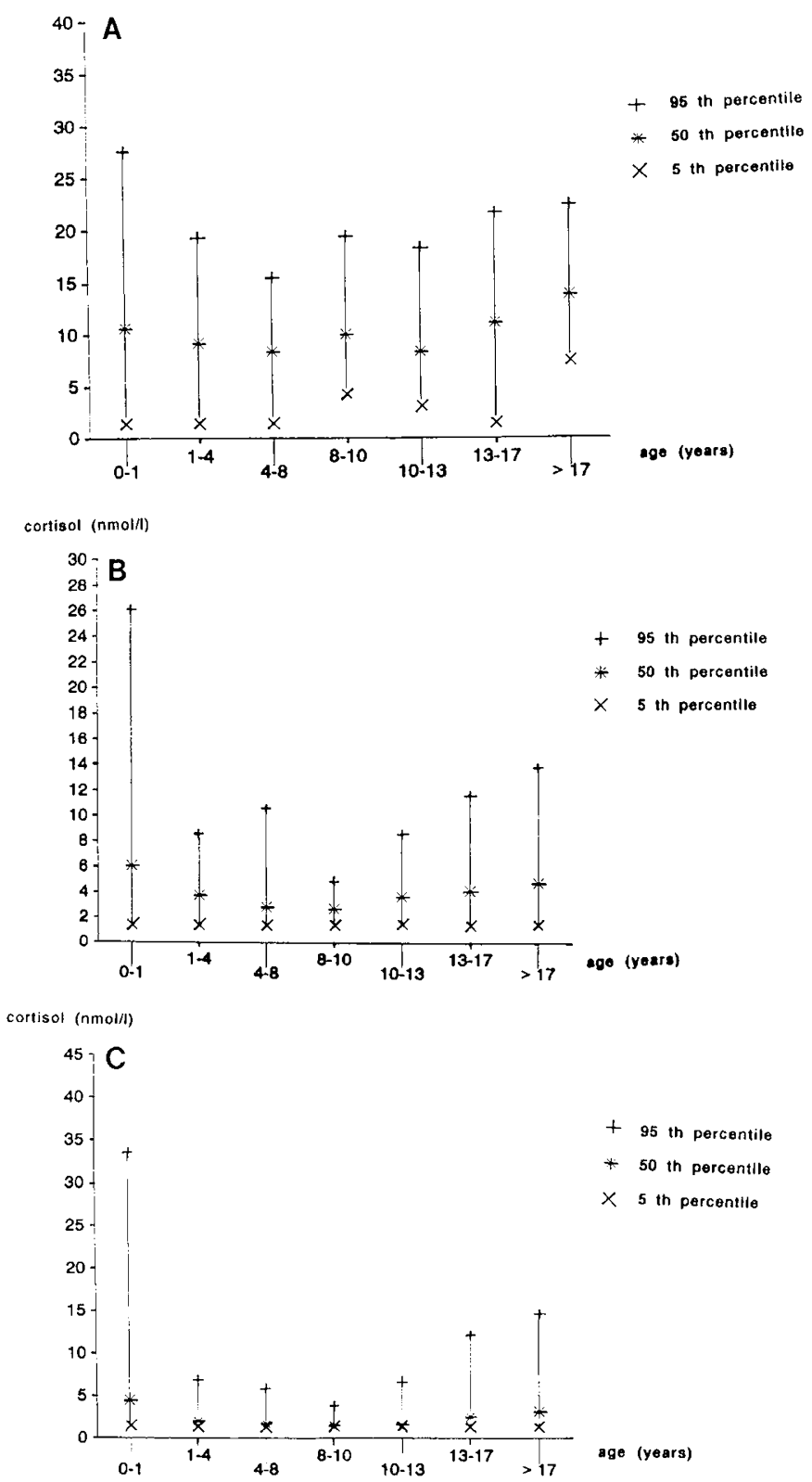

Figure 1. Percentiles of salivary cortisol levels. $A$, Morning salivary cortisol levels; $B$, midday salivary cortisol levels; $C$, cvening salivary cortisol levels (nmol/L) in 152 healthy subjects (age 1 mo to $35 \mathrm{y}$ ). Subjects were $0-1$ y $(n=10)$, above $1-4$ y $(n=17)$, above $4-8$ y $(n=22)$, above $8-10$ y $(n=19)$, above $10-13$ y $(n=33)$, above $13-17$ y $(n=31)$, and above 17 y $(n=20)$. 
Table 1. Daytime variation of salivary cortisol levels (mean $\pm S D$, nmol/L) in 152 healthy subjects

\begin{tabular}{|c|c|c|c|c|c|}
\hline \multirow[b]{2}{*}{ Time } & \multicolumn{5}{|c|}{ Age group (y) } \\
\hline & $\begin{array}{c}0-1 \\
(n=10)\end{array}$ & $\begin{array}{c}>1-5 \\
(n=23)\end{array}$ & $\begin{array}{c}>5-8 \\
(n=23)\end{array}$ & $\begin{array}{c}>8-18 \\
(n=82)\end{array}$ & $\begin{array}{l}>18-35 \\
(n=14)\end{array}$ \\
\hline $1300 \mathrm{~h}$ & $16.7 \pm 32.6$ & $3.8 \pm 2.3$ & $4.9 \pm 4.2$ & $5.0 \pm 6.2$ & $6.2 \pm 3.8$ \\
\hline $1800 \mathrm{~h}$ & $17.5 \pm 29.5$ & $2.6 \pm 1.7$ & $2.7 \pm 2.5$ & $3.1 \pm 3.2$ & $4.3 \pm 3.6$ \\
\hline
\end{tabular}

saliva samples from children over the age of 9 mo. Tables 1 and 2 give the mean $\pm \mathrm{SD}$, mean $\pm \mathrm{SEM}$, and median values of salivary cortisol levels, respectively. The well-known circadian rhythm of cortisol secretion and cortisol metabolism was demonstrable in saliva samples from children and adolescents. However, no such circadian variation was detected when saliva from children under the age of 9 mo was tested (Table 2). In some of these young children cortisol levels in saliva were very high (above $100 \mathrm{nmol} / \mathrm{L}$ ), and occasionally midday or evening cortisol levels exceeded the morning values by up to 5 times (Table 2).

Salivary cortisol levels vary with weight and pubertal stage. Anthropometric data were collected, and salivary cortisol levels were analyzed in relationship to weight, height, body surface $\left(\mathrm{m}^{2}\right)$, and pubcrtal stage of the study subjects. Figure 2 demonstrates a steady decline of the ratio of salivary morning cortisol levels/body surfacc during childhood and adolescence: the larger body surface at higher age is not being compensated for by higher cortisol levels. Figure 3 shows the relationship between salivary cortisol levels and weight. Morning salivary cortisol levels $(\mathrm{nmol} / \mathrm{L})$ are positively correlated with body wcight $(\mathrm{kg})(r=0.28, p<0.001, y=0.08 x+8.1)$ (Fig. 3). When salivary cortisol levels were grouped according to the pubertal stage of donors, a significant, positive correlation between cortisol levels and pubertal stage was measured ( $p<$ 0.0001 up to $p<0.03$, analysis of variance). The positive correlation between cortisol levels and pubertal stages was present irrespective of sampling time (morning, midday, evening) (Table 3).

Table 2. Salivary cortisol levels of 10 healthy infants, aged 1-11

\begin{tabular}{cccc}
\multicolumn{5}{c}{ mo, at day time 0800,1300 , and $1800 \mathrm{~h}$} \\
\multicolumn{4}{c}{ Cortisol level (nmol/L) } \\
\hline Agc (mo) & Morning & Midday & Evening \\
\hline 1 & 21.5 & 107.9 & 97.7 \\
2 & 81.3 & 3.3 & 10.6 \\
2 & 22.8 & 6.0 & 4.5 \\
2 & 7.1 & 7.1 & 3.1 \\
2 & 4.3 & 8.4 & 3.3 \\
5 & 1.4 & 1.4 & 1.4 \\
5 & 10.5 & 2.2 & 2.2 \\
6 & 10.5 & 20.7 & 14.8 \\
9 & 21.0 & 7.6 & 4.2 \\
11 & 16.8 & 1.9 & 5.4 \\
& & & \\
Mcdian & 13.7 & 6.6 & 4.9 \\
Mean \pm SEM & $19.8 \pm 2.3$ & $16.7 \pm 3.3$ & $17.5 \pm 3.0$ \\
Range & $1.4-81.3$ & $1.4-107.9$ & $1.4-97.9$ \\
\hline
\end{tabular}

\section{DISCUSSION}

The measurement of salivary free cortisol levels is a reliable, stress-free, and attractive way of testing adrenal function in infants and children (28-34). It has been shown in the literature (for review, see Refs. 10, 13, and 24) and also in our study that saliva samples can be obtained even from newborns without difficulty in a stress-free and reliable way. We have used the measurement of salivary cortisol to investigate physiologic changes of cortisol metabolism throughout childhood and adolescence. A sensitive, fast, and reliable time-resolved fluorometric immunoassay was used to measure salivary cortisol levels. This assay does not use radioactive tracer and requires only $50 \mu \mathrm{L}$ of saliva for the determination of cortisol. It thus offers additional advantages over comparable methods (27).

High salivary cortisol levels were measured during the first year of life and no circadian variation of salivary cortisol levels was evident during the first 9 mo of life. This result is in agreement with previous results from Price et al. $(13,24)$, who found no circadian variation of salivary and plasma cortisol levels in infants under the age of 3 mo. This finding as well as the data from our study most likely reflect a lack of external synchronization of the newborn circadian rhythm. We cannot determine the exact age at which circadian rhythmicity is detectable due to the small sample numbers in the respective age groups. However, circadian variation of cortisol levels in saliva is certainly already apparent in infants younger than $1 \mathrm{y}$ $(12,13,35)$. The absolute cortisol concentrations in saliva measured in our subjects are within the range that has been reported from other laboratories with the exception that slightly

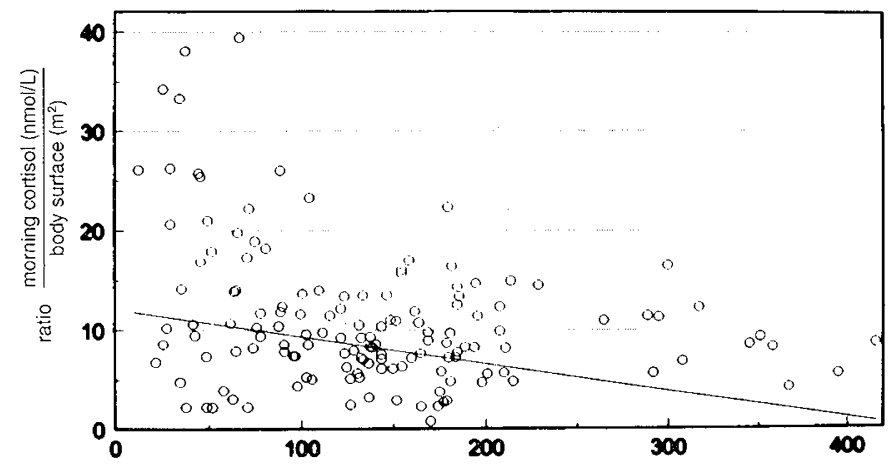

Figure 2. Morning salivary cortisol levels and body surface $\left(\mathrm{m}^{2}\right)$ in relationship to age. Saliva was collected as described in Figure 1 and salivary cortisol was measured by a time-resolved fluorescent immunoassay as described in "Mcthods." The ratio of morning salivary cortisol levels and body surface $\left(\mathrm{m}^{2}\right)$ declines with increasing age $(r=0.30, p<0.001, y=5.23-0.009 x)$. 


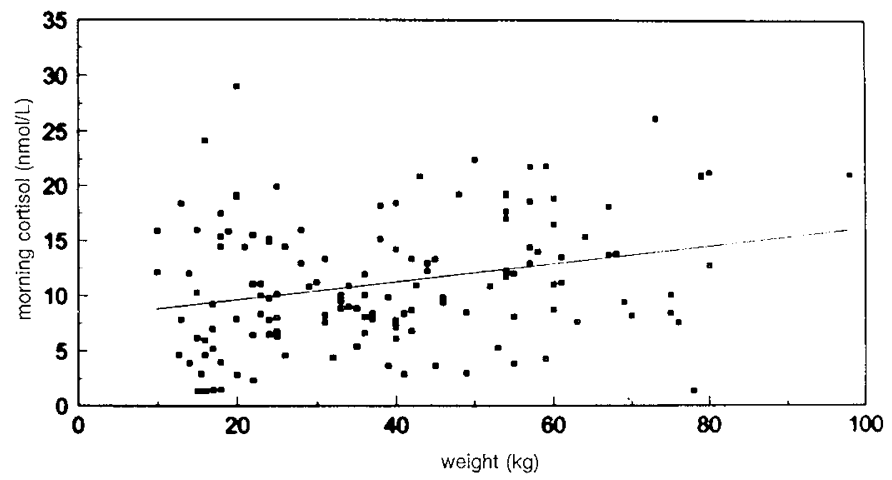

Figure 3. Salivary cortisol levels in relationship to weight. Salivary cortisol of 152 healthy subjects was measured by a time-resolved fluorescent immunoassay as described in "Methods." Morning salivary cortisol levels (nmol/L) are positively correlated with body weight $(\mathrm{kg})(r=0.28, p<0.001, y=(2.88$ $+0.03 x) \times 2.8)$

Table 3. Relationship of salivary cortisol levels (mean $\pm S D$ ) (nmol/L) at day time 0800, 1300, and $1800 \mathrm{~h}$ and pubertal stage in 142 healthy subjects (age above first year of life)

\begin{tabular}{ccccccc}
\hline & \multicolumn{5}{c}{ Pubertal stage } \\
\cline { 2 - 6 } Time & 1 & 2 & 3 & \multicolumn{1}{c}{4} & \multicolumn{1}{c}{5} \\
\hline $0800 \mathrm{~h}$ & $9.9 \pm 5.4$ & $7.6 \pm 4.5$ & $12.4 \pm 4.6$ & $12.5 \pm 7.1$ & $15.0 \pm 5.3$ \\
$1300 \mathrm{~h}$ & $4.1 \pm 2.8$ & $3.6 \pm 2.2$ & $4.6 \pm 2.4$ & $7.1 \pm 4.5$ & $7.3 \pm 9.6$ \\
$1800 \mathrm{~h}$ & $2.5 \pm 2.0$ & $2.6 \pm 1.9$ & $2.4 \pm 1.8$ & $6.2 \pm 4.4$ & $4.3 \pm 4.3$
\end{tabular}

higher cortisol values were detected in the 14 adults in our study (for review, see Refs. 1, 2, 24, and 33). In addition, the quotient of the morning versus the evening level of salivary cortisol is about 3 . This quotient is comparable to the quotient between morning and evening plasma cortisol levels, i.e. a factor of 3-5 (1-2). Inasmuch as plasma cortisol levels increase above the binding capacity of cortisol-binding globulin after pharmacologic ACTH stimulation, the percentage of the increment of salivary cortisol levels after ACTH stimulation is higher than that of plasma cortisol $(33,34)$. Thus the use of salivary cortisol measurements during ACTH stimulation tests may be feasible under clinical conditions.

In our study, salivary cortisol concentrations correlated significantly with pubertal stage. A positive correlation between cortisol levels and pubarche/adrenarche has been reported in two studies in the literature: increased salivary cortisol concentrations in older children and adolescents when compared with infants and prepubertal children have been reported by Gandia et al. (12). In addition, an increased cortisol production rate has been found in adolescents compared with prepubertal children (15).

Interestingly, body weight is positively related to salivary cortisol levels throughout childhood, adolescence, and young adult life: with increasing body weight of the study subjects, an increase in morning cortisol levels was measured. However, body surface is not positively correlated with salivary cortisol levels: the larger body surface in older subjects apparently is not compensated for by higher cortisol levels, although the overall cortisol levels increase with age. This result might indicate either a lower production rate or a higher rate of metabolism or clearance of cortisol with increasing age (15). Again, the results shown in Figures 2 and 3 indicate that weight rather than body surface correlates with increased cortisol production and/or decreased cortisol degradation and metabolism. This relationship has to be taken into consideration if salivary cortisol measurements are used in the clinical setting, i.e. for screening for Cushing's disease in obese individuals. Multivariate regression analysis showed that weight, age, and pubertal stage were independently and to an equal extent correlated with salivary cortisol levels (data not shown). However, we do not assume that the dominant factors influencing cortisol production or elimination rates can be assessed properly in our still rather small sample of healthy individuals. Further investigations with the study of larger numbers of healthy individuals as well as patients with adrenal disease will be required to answer the question of which nonhormonal factors predominantly influence salivary cortisol levels.

Because salivary cortisol levels correlated with pubertal stages of the study subjects, one could assume that crossreactivity of the cortisol antiserum with sex steroids might mimic such a positive correlation, inasmuch as sex steroids will increase during puberty. Alternatively, the increased salivary cortisol levels in puberty might reflect a higher overall hormonal activity of the adrenal gland throughout puberty. Third, higher cortisol levels might be required later in puberty and postpubertal life, as well as in the neonatal period than during prepubertal childhood, a state that is characterized by apparent relative hormonal stability and "inactivity." Because the cortisol antiserum used in this study is highly specific for cortisol (26), cross-reactivity of the assay with sex steroids is unlikely to have occurred.

It has been suggested that in the salivary gland cortisol is readily converted into cortisone. However, because free cortisol rapidly diffuses from plasma into saliva, salivary cortisol levels are thought to reflect free plasma cortisol, and the influence of cortisone cross-reactivity seems to be low. If one assumes a cortisone:cortisol ratio in saliva of $1: 1$, the positive bias of cortisone in our assay would still be only about $5 \%$, taking the $11 \%$ cross-reactivity of our assay with cortisone into account.

In summary, a highly sensitive time-resolved immunofluorescence assay was used to establish reference values for salivary cortisol levels in healthy children and adolescents. Although salivary cortisol levels vary greatly, the calculated reference percentiles will help to establish this noninvasive technique to monitor adrenal function under clinical and pathologic conditions (36-41).

Acknowledgments. The authors acknowledge the critical discussion of the data by Drs. W. Sippell, Kiel, Germany, and Dr. H. B. Hadorn, Munich, Germany. The authors are especially grateful for the kind collaboration and support from the study subjects and their parents. The generous supply of saliva collecting tubes (Salivette) by Sarstedt, Germany, is appreciated. The authors express their sincere gratitude to Dr. W. Rascher, Giessen, FRG, for support and guidance. 


\section{REFERENCES}

1. Kirschbaum C, Hellhammer DH 1989 Salivary cortisol in psychobiological research: an overview. Neuropsychobiology 22:150-169

2. Kirschbaum C 1991 Cortisolmessung im Speichel-eine Methode der biologischen Psychologie. Verlag H. Hubcr, Seattle

3. Hiramatsu R 1981 Direct assay of cortisol in human saliva by solid phase radioimmunoassay and its clinical applications. Clin Chim Acta 117:239-242

4. Vining RF, McGinley RA, Maksvytis JJ, Ho KY 1983 Salivary cortisol: a better measurement of adrenal function than serum cortisol. Ann Clin Biochem 20:329-341

5. Riad-Fahmy D, Read GF, Walker RF, Griffiths K 1982 Steroids in saliva for assessing endocrine function. Endocr Rev 3:367-395

6. Burke PM, Reichler RJ, Smith E, Dugaw K, McCauley E, Mitchell J 1985 Correlation between serum and salivary cortisol levels in depressed and non-depressed children and adolescents. Am J Psychiatry 142:1065-1067

7. Evans PJ, Peters JR, Dyas J, Walker RF, Riad-Fahmy D, Hall R 1984 Salivary cortisol levels in true and apparent hypercortisolism. Clin Endocrinol 20:709-715

8. Guechot J, Fiet J, Passa P, Villette JM, Gourmel B, Tabuteau F, Cathelineau G, Dreux C 1982 Physiological and pathological variation in saliva cortisol. Horm Res 16:357364

9. Laudat MH, Cerdas S, Fournier C, Guiban D, Guilhaume B, Luton JP 1988 Salivary cortisol measurement: a practical approach to assess pituitary-adrenal function. J Clin Endocrinol Metab 66:343-348

10. Walker RF 1989 Salivary corticosteroids: clinical and research applications. J Clin Chem Clin Biochem 27:234-235

11. Malamud D, Tabak L 1993 Saliva as a diagnostic fluid. Ann NY Acad Sci 694:1-343

12. Gandia A, Bolufer P, Rodriguez A, Antonio P 1990 Salivary cortisol increases with age in children. J Clin Chem Clin Biochem 28:655

13. Price DA, Close GC, Fielding BA 1983 Age of appearance of circadian rhythm in salivary cortisol values in infancy. Arch Dis Child 58:454-456

14. Kerrigan JR, Veldhuis JD, Leyo SA, Iranmanesh A, Rogol AD 1993 Estimation of daily cortisol production and clearance rates in normal pubertal males by deconvolution analysis. J Clin Endocrinol Metab 76:1505-1510

15. Linder BL, Esteban NV, Yergey AL, Winterer JC, Loriaux DL, Cassorla F 1990 Cortisol production rate in childhood and adolescence. J Pediatr 117:892-896

16. Gomez MT, Malozowski S, Winterer J, Vamvakopoulos NC, Chrousos GP 1991 Urinary free cortisol values in normal children and adolescents. J Pediatr 118:256258

17. Bober JF, Weller EB, Tait A, Fristad MA, Prekorn SH 1988 Correlation of serum and salivary cortisol levels in prepubertal school-aged children. J Am Acad Child Adolesc Psychiatry 27:748 -750

18. Bustamente B, Crabbe J 1984 Parotid saliva cortisol in normal subjects: increase during pregnancy. J Stcroid Biochem 20:133-136

19. Forest MG 1978 Age-related responses of plasma testosterone, delta4 androstendione, and cortisol to ACTH in infants, children and adults. $\mathrm{J}$ Clin Endocrinol Metab 47:931-937

20. Francis SJ, Walker RF, Riad-Fahmy D, Hughes D, Murphy JF, Gray OP 1987 Assessment of adrenocortical activity in term newborn infants using salivary cortiso determination. J Pediatr 111:129-133

21. Hampl R, Foretova L, Sulcova J, Starka L 1990 Daily profiles of salivary cortisol in hydrocortisone treated children with CAH. Eur J Pediatr 149:232-234

22. Magnano CL, Diamond EJ, Gardner JM 1989 Use of salivary cortisol measurement in young infants: a note of caution. Child Dev 60:1099-1101
23. Magnano CL, Gardner JM, Karmel BZ 1992 Differences in salivary cortisol levels in cocoaine-exposed and non-cocaine exposed NICU infants. Dev Psychobiol 25:93103

24. Price DA 1984 Salivary hormone levels in infants and children. In: Kawamura Y Ferguson DB (eds): Frontiers in Oral PhYsiology: Steroid Hormones in Saliva. S. Karger Verlag, Basel, pp 51-66

25. Woodside DB, Winter K, Fisman S 1991 Salivary cortisol in children: correlations with serum values and effect of psychotropic drug administration. Can J Psychiatry 36:746-748

26. Prader A, Largo RH, Molinari L, Issler RH 1989 Physical growth in Swiss children from birth to 20 years of age. Helv Paediatr Acta Suppl 52:1-12

27. Dressendörfer RA, Kirschbaum C, Rohde W, Stahl F, Strasburger CJ 1992 Synthesis of a cortisol-biotin conjugate and evaluation as a tracer in an immunoassay for salivary cortisol measurement. J Steroid Biochem Mol Biol 43:683-692

28. Woolston JL, Gianfredi S, Gertner JM, Paugus JA, Mason JW 1983 Salivary cortisol: a nontraumatic sampling technique for assaying cortisol dynamics. J Am Acad Child Psychiatry 22:474-476

29. Walker RF, Riad-Fahmy, Read GF 1978 Adrenal status assessed by direct RIA of cortisol in whole saliva or parotid saliva. Clin Chem 24:1460-1463

30. Vining RF, McGinley RA 1986 Hormones in saliva. Crit Rev Clin Lab Sci 23:95-146

31. Vining RF, McGinley RA 1984 Flux of steroids between blood and saliva. In: Kawamura Y, Ferguson DB (eds) Frontiers of Oral Physiology: Steroid Hormones in Saliva. S. Karger, Basel, pp 21-32

32. Meulenberg PM, Hofman JA 1990 Differences between concentrations of salivary cortisol and cortisone and of free cortisol and cortisone in plasma during pregnancy and postpartum. Clin Chem 36:70-75

33. Peters JR, Hall R, Walker RF, Riad-Fahmy D 1988 Salivary cortisol: 2. monitoring changes in abnormal adrenal activity. In: Read GF, Riad-Fahmy D, Walker RF, Griffiths K (eds) Immunoassays of Steroids in Saliva. Alpha Omega, Cardiff, UK pp 317-321

34. Luisi M, Franchi F 1984 Salivary steroid measurements. An alternative approach to plasma assays in assessing endocrine function. In: Kawamura Y. Ferguson DB (eds) Frontiers of Oral Physiology: Steroid Hormones in Saliva. S. Karger, Basel, pp $124-155$

35. Lacerda LD, Kowarski A, Migeon CJ 1973 Integrated concentration and diurnal variation of plasma cortisol J Clin Endocrinol Metab 36:227-238

36. Williams H, Read GF, Verrier-Jones ER, Hughes IA 1984 Effect of inhaled beclomethasone dipropionate on saliva cortisol concentrations. Arch Dis Child 59:553556

37. Foreman DM, Goodyer IM 1988 Salivary cortisol hypersecretion in juvenile depression. J Child Psychol Psychiatry 29:311-320

38. Hanada K., Yamada N, Shomoda K, Takahashi S 1985 Direct RIA of cortisol in saliva and its application to the dexamethasone suppression test in affective disorders. Psychoneuroendocrinology 10:193-201

39. Wilson DM, Baldwin RB, Ariagno RL 1988 A randomized, placebo-controlled trial of effects of dexamethasone on hypothalamic-pituitary-adrenal axis in preterm infants. J Pediatr 113:764-768

40. Schlaghecke R, Kornely E, Santen RT, Ridderskamp P 1992 The effect of long-term glucocorticoid therapy on pituitary-adrenal responses to exogenous corticotropinreleasing hormone. N Engl J Med 326:226-230

41. Chen YM, Cintron NM, Whitson PA 1992 Long-term storage of salivary cortisol samples at room temperature. Clin Chem 38:304 